\title{
Informal carers' health-related quality of life and patient experience in primary care: evidence from 195,364 carers in England responding to a national survey
}

\author{
Gwilym P.A. Thomas ${ }^{1}$, Catherine L. Saunders' ${ }^{2}$ Martin O. Roland ${ }^{1}$ and Charlotte A.M. Paddison ${ }^{1,3^{*}}$
}

\begin{abstract}
Background: We aim to describe the health-related quality of life of informal carers and their experiences of primary care. Methods: Responses from the 2011-12 English General Practice Patient Survey, including 195,364 informal carers, were analysed using mixed effect logistic regressions controlling for age, gender, ethnicity and social deprivation to describe carer health-related quality of life (mobility, self-care, usual activities, pain, and anxiety/depression, measured using EQ-5D) and primary care experience (access, continuity and communication).

Results: Informal carers reported poorer health-related quality of life than non-carers of similar age, gender, ethnicity and social deprivation. Increasing caring commitment was associated with worse EQ-5D scores, with carers of 50+ hours a week scoring 0.05 points lower than non-carers ( $95 \%$ Cl 0.05 to 0.04 ), equivalent to 18 fewer days of full health annually. Considering each domain of EQ-5D separately, carers of 50+ hours/week were more likely to report pain $\mathrm{OR}=1.53$ (1.50-1.57), $p<0.0001$, and anxiety/depression $\mathrm{OR}=1.69$ (1.66-1.73), $p<0.0001$, than non-carers. Younger carers scored lower on EQ-5D than non-carer peers but the converse was true among over-85s. In the most deprived areas carers reported the equivalent of 37 fewer days of full health annually than carers in the most affluent areas. On average, carers reported poorer patient experiences in all areas of primary care than non-carers (odds ratios 0.84-0.97), with this difference being most marked in the domain of access.

Conclusions: Informal carers experience a double disadvantage of poorer health-related quality of life and poorer patient experience in primary care. We find no evidence for health benefits of caregiving. We recommend physicians identify and treat carer health problems, including pain and anxiety/depression, particularly among young, deprived and high time-commitment carers. Improving patient experience for carers, including access to primary care, should be a priority.
\end{abstract}

Keywords: Carers, Primary care, Health-related quality of life, Patient experience, Caregivers

\section{Background}

Promoting and protecting the health and wellbeing of informal carers is an important public health priority for both pragmatic and ethical reasons $[1,2]$, and the provision of high quality primary care services for carers is central to such efforts $[3,4]$.

\footnotetext{
* Correspondence: camp3@medschl.cam.ac.uk

'Cambridge Centre for Health Services Research Primary Care Unit, University of Cambridge, Cambridge, UK

${ }^{3}$ Department of Psychology, Anglia Ruskin University, Cambridge, UK

Full list of author information is available at the end of the article
}

Informal carers comprise between 10 and $30 \%$ of the population of developed nations [5-7], and perform important social and economic roles $[8,9]$. The economic value of informal caring has been estimated at $£ 119$ billion per year in the UK [10] and US\$ $\$ 50$ billion in the USA [11]. Informal care is set to take on an increasingly important role in supporting formal health services due to demographic changes associated with population aging and increasing financial pressures on healthcare $[9,12,13]$.

Informal carers experience poorer physical and mental health $[5,8,14-21]$ than non-carers. Greater care 
commitments, for example weekly time commitment or duration of caring responsibility [22, 23], are associated with increasingly poorer health. There is evidence that the burden of caring is most acute among marginalised groups, for example those who are socially isolated [24], or of lower socioeconomic status [25].

Recent analyses have suggested that caregiving is associated with lower mortality [26, 27], and some studies have suggested that low burden caring may benefit the health or wellbeing of the carer $[28,29]$. Further empirical studies are needed to test for evidence supporting the 'caring confers health benefit" hypothesis and alternative explanations including the role of selection factors $[30,31]$ which determine who is able to undertake a caring role.

Previous research examining carers' healthcare experiences has focused on their carer role [32]: the primary care experiences that carers report for themselves as patients remains unknown. Patient experience is an important dimension of care quality [33, 34], and knowledge of the patients' experience can help to inform improvements in care.

This study aims to describe the health-related quality of life and primary care experiences of informal carers in England responding to the national General Practice Patient Survey, and to examine variation among carers reported by socio-demographic characteristics and level of caregiving commitment.

\section{Methods}

The English General Practice Patient Survey (GP Patient Survey), a national primary-care based survey commissioned by the English Department of Health, is mailed annually to approximately 2.7 million patients who have been continuously registered with a general practice in England for at least six months. A random sample from each general practice in England is selected, stratified by age and gender; registered patients from practices which have typically had low response rates in previous years are over-sampled. Further details on the survey have been published [35-37].

\section{Measures \\ Caring}

A single question was included in the GP Patient Survey from 2011 to identify informal carers, and measure caring commitment in terms of hours per week spent caring. Survey respondents were asked 'Do you look after, or give any help or support to family members, friends or neighbours because of either: long-term physical or mental ill health/disability, or problems related to old age?" Asked to discount anything they do as part of paid employment, respondents chose one of six response options: No; Yes, 1-9 hours a week; Yes, 10-19 hours a week; Yes, 20-34 hours a week; Yes, 35-49 hours a week; Yes, 50+ hours a week.

\section{Health-related quality of life}

Health-related quality of life was measured using the EuroQol five-dimension (EQ-5D) [38]. This standardised and well-validated measure [39] asks respondents to rate their health-related quality of life on five dimensions (mobility; self-care; usual activities; pain/discomfort; and anxiety/depression) with 3 response options corresponding to no, moderate, or severe problems for each dimension. Multiplied by 365, EQ-5D scores represent a standardized health utility score, interpretable as the number of days of full health experienced per year [39].

\section{Patient experience}

A single question was used to assess overall patient experience in primary care. Six additional items assessed patient experience in three domains: access (two questions); continuity of care (one question); and communication (receptionist communication (one question), doctor communication and, separately, nurse communication (one question with five sub-items for each)). Response options were provided on five- and six-point likert scales.

Patient experience outcomes were categorized using a binary indicator (yes/no) for "positive experience of care" consistent with the public reporting of GP Patient Survey data [40]. For questions on doctor and nurse communication we only included responses where at least three of the five sub-items were completed, coding an overall positive experience where all completed responses were either "very good" or "fairly good". Detail on survey questions is provided in Additional file 1: Table S1.

\section{Socio-demographic characteristics}

Socio-demographic characteristics measured in the survey included self-reported gender (male/female); age (eight ordinal categories from 18-24, 25-34 to 85+); ethnicity using the UK Office of National Statistics categories of White; Mixed; Asian; Black; Other [41]) and socioeconomic status based on linking the respondent's postal code to the Lower Super Output Area Index of Multiple Deprivation, a smallarea measure of deprivation [42].

\section{Analysis}

We described the characteristics of informal carers and non-carers who responded to GP Patient Survey by calculating weighted percentages. The associations between caring and health-related quality of life, and between caring and carer patient experience in primary care, were investigated using mixed effect regression models adjusted for age, gender, deprivation, and ethnicity using fixed effects, and additionally for primary care practice using a random effect. We compared respondents without caring commitments to carers, both overall and using five ordinal 
categories to investigate differences among carers by number of hours spent caring per week.

To explore whether the association between caring and health-related quality of life, or caring and carer patient experience, varied between different groups of carers, we carried out a further series of models which included interaction terms for age, gender, deprivation and ethnicity. We also explored the socio-demographic predictors of poorer health and poorer patient experience among carers alone.

For the analysis of health-related quality of life, we ran models which included each dimension of EQ-5D as a separate outcome. For patient experience outcomes only, as a sensitivity analysis, we explored whether the association between caring and patient experience could be explained by the poorer health-related quality of life of carers.

For one question we predicted adjusted percentages of carers and non-carers reporting a positive overall experience of primary care, these being the percentages we would expect to report a positive experience if the socio-demographic case-mix were the same as all included responders.

Multivariable analyses were carried out on respondents with complete data on socio-demographic characteristics and EQ-5D (855,330 responses including 174,035 carers). Stata 11 was used for all analyses. The GP Patient Survey is a service evaluation which does not require research ethics committee approval for its use.

\section{Results}

1,037,946 responses to the 2011-12 English GP Patient Survey were received from patients registered with 8258 primary care practices (37.8\% survey response rate). 959,997 respondents provided a valid answer to the question about informal caring, of whom 195,364 (20.4 \%) reported that they were informal carers, with 64,416 (33.0 \%) indicating that their caring commitments exceeded 20 hours per week.

Demographic and health characteristics of the 195,364 respondents who self-reported as carers are displayed in Table 1. Carers were more likely to be older and female. Informal carers with higher caring time commitments were more likely to live in socially-deprived areas than carers with low time commitments.

\section{Health-related quality of life among carers}

On average, carers reported poorer health-related quality of life that non-carers (weighted mean EQ-5D scores 0.81 and 0.84 , respectively), with this difference interpretable as carers experiencing 11 fewer days of full health per year. Table 2 shows the difference in health-related quality of life for carers, compared to non-carers of similar age, gender, ethnicity, and level of social deprivation. Those with 50+ hours per week of caring commitment experience report worse health-related quality of life than non-carers (adjusted mean difference -0.05 (95 \% CI-0.05 to-0.04)), interpretable as 18 fewer days of full health per year.

Carers aged under 45 score worse on EQ-5D than noncarers; those over 85 tend to score better (Fig. 1). Overall and within each age group, however, the effect of increasing caring commitment is a reduction in health-related quality of life.

Carers of 50+ hours/week were more likely to report pain OR $=1.53$ (1.50-1.57), $\mathrm{p}<0.0001$, and anxiety/depression $\mathrm{OR}=1.69(1.66-1.73), \mathrm{p}<0.0001$ than non-carers. When stratified by age, older carers at all levels of caring commitment were more likely to report pain, depression and anxiety, but reported better mobility and self-care ability than non-carers (Additional file 1: Figure S1).

For gender, deprivation and ethnicity, there was evidence of variation in the association between caring and healthrelated quality of life, although without consistent trends between groups. We therefore explored the association between socio-demographic characteristics and poorer health-related quality of life among carers alone (Table 3). This analysis showed differences in EQ-5D among carers by level of social deprivation and age, equivalent to 37 fewer days of full health per year for carers in the most deprived areas, compared to the most affluent, and 44 fewer days of full health among those aged 85+ compared with the 55-64 year old reference group.

\section{Patient experience among carers}

Informal carers reported less positive patient experiences for all seven patient experience questions than noncarers, even after accounting for socio-demographic and health factors known to affect such experiences (odds ratios range: 0.84-0.97), with access the area where, compared with non-carers, patient experience is reported to be poorest. When asked a single question on overall experience in primary care, carers were between 1.0 and $3.7 \%$ less likely (adjusted percentages, varying by level of caring commitment) to report a positive experience than non-carers.

Among carers, there was some evidence of a trend showing that the likelihood of reporting a positive patient experience increased with higher levels of caring commitment (Fig. 2). Although all carers reported poorer access to healthcare (telephone access and making an appointment) than non-carers, those with caring commitments of over 50 hours per week rated their experiences more positively than non-carers in the domains of continuity and doctor communication (OR 1.07 (CI 1.03 to 1.1) and 1.04 (CI 1.01 to 1.07) respectively).

Controlling for health-related quality of life (EQ-5D) did not change the interpretation of observed associations between caring and patient experience (Additional file 2: Table S2). 
Table 1 Demographic characteristics of patients with caring responsibilities among 2012 General Practice Patient Survey responders

\begin{tabular}{|c|c|c|c|}
\hline & $\begin{array}{l}\text { Self-reported carers } \\
(\geq 20 \text { hours per week) } \\
N\left(\text { weighted \%) }{ }^{a} \text { (total } n=64,416\right)\end{array}$ & $\begin{array}{l}\text { Self-reported carers } \\
(<20 \text { hours per week)' } \\
\text { N (weighted \%) }{ }^{a}(\text { total } n=130,948)\end{array}$ & $\begin{array}{l}\text { Responders without caring } \\
\text { responsibilities } N \text { (weighted \%) } \\
\text { a(total } n=764,633 \text { ) }\end{array}$ \\
\hline \multicolumn{4}{|l|}{ Gender } \\
\hline Male & $25,466(44.3)$ & $51,736(45.0)$ & $336,635(50.6)$ \\
\hline Female & $37,680(55.7)$ & $77,464(55.0)$ & $416,938(49.4)$ \\
\hline \multicolumn{4}{|l|}{ Age group } \\
\hline $18-24$ & $1,141(4.3)$ & $3,506(6.0)$ & $40,138(11.0)$ \\
\hline $25-34$ & $3,061(9.1)$ & $7,266(9.9)$ & $90,015(19.4)$ \\
\hline $35-44$ & $6,789(15.6)$ & $14,824(15.6)$ & $114,513(19.5)$ \\
\hline $45-54$ & $11,300(21.1)$ & $32,379(27.3)$ & $128,503(17.4)$ \\
\hline $55-64$ & $15,309(20.6)$ & $38,906(24.4)$ & $142,044(13.6)$ \\
\hline $65-74$ & $13,958(15.7)$ & $22,711(11.8)$ & $131,974(10.4)$ \\
\hline $75-84$ & $9,418(10.8)$ & $8,328(4.3)$ & $79,584(6.2)$ \\
\hline $85+$ & $2,206(2.8)$ & $1,295(0.7)$ & $26,544(2.5)$ \\
\hline \multicolumn{4}{|l|}{ Ethnic group } \\
\hline White & $56,212(87.9)$ & $118,345(90.7)$ & $658,587(86.9)$ \\
\hline Mixed & $404(0.8)$ & $775(0.7)$ & $5,967(1.0)$ \\
\hline Asian ${ }^{b}$ & $3,704(6.4)$ & $5,698(5.2)$ & $47,823(6.7)$ \\
\hline Black $^{c}$ & $1,236(2.1)$ & $2,189(1.7)$ & $21,248(2.8)$ \\
\hline Other ethnic group & $1,597(2.8)$ & $1,956(1.6)$ & $18,780(2.5)$ \\
\hline \multicolumn{4}{|l|}{ Socio-economic deprivation } \\
\hline 1 (Affluent) & $9,516(15.0)$ & $30,424(23.2)$ & $147,459(19.9)$ \\
\hline 2 & $11,764(17.3)$ & $30,626(22.3)$ & $155,496(19.8)$ \\
\hline 3 & $13,141(19.8)$ & $27,911(20.4)$ & $156,665(20.0)$ \\
\hline 4 & $13,683(21.5)$ & $22,850(18.1)$ & $150,733(20.2)$ \\
\hline 5 (Deprived) & $16,270(26.6)$ & $19,063(16.0)$ & $153,733(20.1)$ \\
\hline \multicolumn{4}{|l|}{ Health-related quality of life } \\
\hline Mobility: No problems & $40,898(70.4)$ & $102,790(83.4)$ & $560,632(81.8)$ \\
\hline Some or severe problems & $20,704(29.6)$ & $24,416(16.6)$ & $178,344(18.2)$ \\
\hline Self-care: No problems & $54,973(90.4)$ & $121,465(95.9)$ & $671,424(93.0)$ \\
\hline Some or severe problems & $6,467(9.6)$ & $5,748(4.1)$ & $66,218(7.0)$ \\
\hline Usual activities: No problems & $39,545(66.9)$ & $98,595(78.9)$ & $555,514(79.6)$ \\
\hline Some or severe problems & $22,160(33.1)$ & $28,780(21.1)$ & $183,891(20.4)$ \\
\hline Pain/discomfort: None & $25,386(45.3)$ & $68,766(57.3)$ & $419,714(63.7)$ \\
\hline Moderate or extreme pain/discomfort & $36,021(54.7)$ & $58,100(42.7)$ & $316,938(36.3)$ \\
\hline Anxiety/depression: None & $39,076(64.6)$ & $94,086(74.3)$ & $556,103(77.5)$ \\
\hline Moderate or extreme anxiety/depression & $21,093(35.4)$ & $31,424(25.7)$ & $170,633(22.5)$ \\
\hline \multicolumn{4}{|l|}{ Number long-term conditions } \\
\hline 0 & $22,039(39.4)$ & $57,657(48.7)$ & $351,412(54.6)$ \\
\hline 1 & $19,155(29.2)$ & $41,460(30.7)$ & $218,265(26.4)$ \\
\hline
\end{tabular}


Table 1 Demographic characteristics of patients with caring responsibilities among 2012 General Practice Patient Survey responders (Continued)

\begin{tabular}{llll}
\hline 2 & $12,075(16.8)$ & $19,540(13.1)$ & $106,832(10.9)$ \\
3 & $6,335(8.3)$ & $7,959(4.9)$ & $51,457(4.8)$ \\
4 or more & $4,812(6.3)$ & $4,332(2.6)$ & $36,667(3.3)$ \\
\hline
\end{tabular}

${ }^{a}$ Weighted percentages are calculated using survey design and non-response weights (by age, gender, geographical location and GP practice, full details Technical Annex GP Patient Survey 2011-2012 Annual Report)

${ }^{\mathrm{b}}$ Indian, Pakistani, Bangladeshi, any other Asian background

c Black Caribbean, Black African, any other Black background

In the same way as for health-related quality of life (Table 3), predictors of poorer patient experience among carers were explored (Table 4). Younger age was the strongest predictor of poorer patient experience among carers. Compared with the reference group of 55-64 years, the youngest carers (18-24 years) reported the poorest patient experience (OR 0.38 (CI 0.35 to 0.41 )).

\section{Discussion}

Informal carers in England experience a double disadvantage of poorer health and worse patient experience in primary care when compared to non-carers of similar age, gender, ethnicity and level of social deprivation in a study of 195,364 carers responding to a national primary care-based survey.

\section{Health-related quality of life among carers}

An association between caring and poorer health or quality of life is well-established from previous research $[14,15,17,23]$. Our results add to what is already known by highlighting variation in this relationship by age; younger carers, particularly those aged under 45 , reported poorer health-related quality of life than similarly-aged non-carers. The health needs of younger carers, which may be different from those of older carers [17, 43], can be identified as an important strategic priority for interventions aiming to improve carer health. In absolute terms, older carers nevertheless experience poorer health-related quality of life than younger carers, commensurate with their ageing.

\section{Health-related quality of life: evidence of benefits from caring?}

Previous research has suggested that informal carers, particularly those with lower caring burdens, may experience health benefits from their role [26-29]; our results provide no additional evidence for this. Carers with higher caring time commitments report poorer healthrelated quality of life (EQ-5D) than those with lower time commitments, consistently across all age groups and the five dimensions of EQ-5D. However older carers in our study report better health-related quality of life than non-carers of similar age, particularly in the physical dimensions of EQ-5D. We suggest that this could be a consequence of carers often having to meet certain physical demands in order to assume a caring role; our results are more consistent with a process of selfselection based on physical capability making carers appear healthier [30, 31] than caring conferring significant social or psychological benefits.

\section{Disparities in health-related quality of life among informal carers}

Carers living in the most deprived areas reported worse health-related quality of life than less deprived carers, even after controlling for other socio-demographic characteristics. This finding suggests that additional factors, such as available social capital, may be important in explaining disparities in health-related quality of life among carers. Consistent with this, previous studies have suggested that the presence of social support may reduce the burden experienced by carers [44] and can improve health outcomes for economically deprived individuals [45].

Table 2 Health-related quality of life (measured by EQ-5D) by number of hours caring per week

\begin{tabular}{lcc}
\hline Caring commitment (hours/week) & Unadjusted mean EQ-5D (95 \%Cl) & Adjusted $^{\mathrm{a}}$ mean EQ-5D $(95 \% \mathrm{Cl})^{\circ}$ \\
\hline 0 & $0.81(0.81-0.81)$ & $0.81(0.81-0.81)$ \\
$1-9$ & $0.84(0.84-0.84)$ & $0.83(0.83-0.83)$ \\
$10-19$ & $0.80(0.80-0.81)$ & $0.81(0.81-0.81)$ \\
$20-34$ & $0.77(0.77-0.78)$ & $0.79(0.78-0.79)$ \\
$35-49$ & $0.75(0.75-0.76)$ & $0.77(0.77-0.78)$ \\
$50+$ & $0.73(0.72-0.73)$ & $0.77(0.76-0.77)$ \\
\hline
\end{tabular}

${ }^{a}$ Mean EQ-5D score after adjustment for gender, age, ethnicity, and social deprivation 


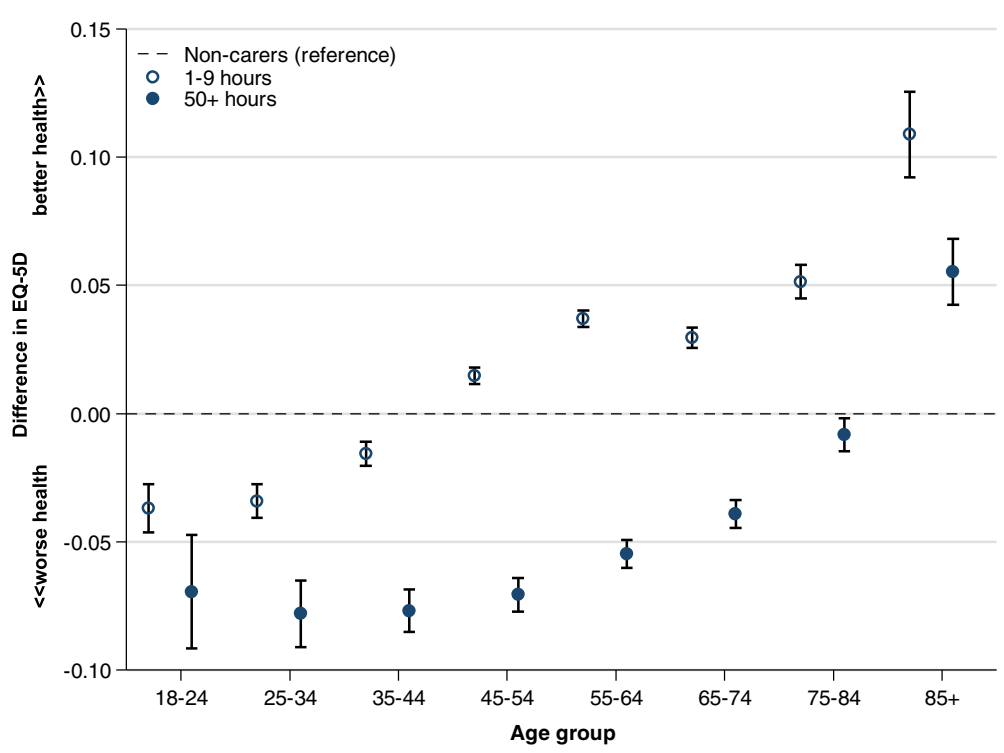

Fig. 1 Difference in health-related quality of life among carers compared with non-carers, stratified by age; Health-related quality of life measured using EQ-5D

Table 3 Differences in health-related quality of life among carers

\begin{tabular}{|c|c|c|c|c|}
\hline & EQ-5D-predictors among carers(unadjusted) & $\mathrm{p}$-value & EQ-5D-predictors among carers(adjusted) ${ }^{\mathrm{a}}$ & p-value \\
\hline \multicolumn{5}{|l|}{ Gender } \\
\hline Male & ref & $<0.0001$ & ref & $<0.0001$ \\
\hline Female & 0.01 (0.00 to 0.01$)$ & & $0.00(-0.01$ to 0.00$)$ & \\
\hline \multicolumn{5}{|l|}{ Age group } \\
\hline $18-24$ & 0.06 (0.05 to 0.07 ) & $<0.0001$ & 0.07 (0.06 to 0.08$)$ & $<0.0001$ \\
\hline $25-34$ & 0.05 (0.05 to 0.06$)$ & & 0.07 (0.06 to 0.07 ) & \\
\hline $35-44$ & 0.03 (0.03 to 0.04$)$ & & 0.04 (0.04 to 0.04$)$ & \\
\hline $45-54$ & 0.02 (0.01 to 0.02 ) & & 0.02 (0.01 to 0.02 ) & \\
\hline $55-64$ & ref & & ref & \\
\hline $65-74$ & $-0.03(-0.03$ to -0.03$)$ & & $-0.02(-0.03$ to -0.02$)$ & \\
\hline $75-84$ & $-0.08(-0.09$ to -0.08$)$ & & $-0.06(-0.07$ to- -0.06$)$ & \\
\hline $85+$ & $-0.14(-0.15$ to -0.13$)$ & & $-0.12(-0.12$ to -0.11$)$ & \\
\hline \multicolumn{5}{|l|}{ Ethnic group } \\
\hline White & ref & $<0.0001$ & ref & $<0.0001$ \\
\hline Mixed & $-0.01(-0.02$ to 0.01$)$ & & $-0.02(-0.03$ to 0.00$)$ & \\
\hline Asian & 0.02 (0.01 to 0.02 ) & & 0.01 (0.01 to 0.02$)$ & \\
\hline Black & 0.01 (0.00 to 0.02 ) & & 0.02 (0.01 to 0.03 ) & \\
\hline Other ethnic group & $-0.02(-0.03$ to -0.01$)$ & & $-0.02(-0.03$ to -0.01$)$ & \\
\hline \multicolumn{5}{|c|}{ Socio-economic deprivation } \\
\hline 1 (Affluent) & ref & $<0.0001$ & ref & $<0.0001$ \\
\hline 2 & $-0.02(-0.02$ to -0.01$)$ & & $-0.01(-0.02$ to -0.01$)$ & \\
\hline 3 & $-0.03(-0.04$ to -0.03$)$ & & $-0.03(-0.03$ to -0.03$)$ & \\
\hline 4 & $-0.06(-0.06$ to -0.06$)$ & & $-0.06(-0.06$ to -0.06$)$ & \\
\hline 5 (Deprived) & $-0.10(-0.10$ to -0.09$)$ & & $-0.10(-0.10$ to -0.09$)$ & \\
\hline
\end{tabular}

${ }^{a}$ The results from this model are presented adjusted for level of caring commitment, age, gender, deprivation, ethnicity and general practice 


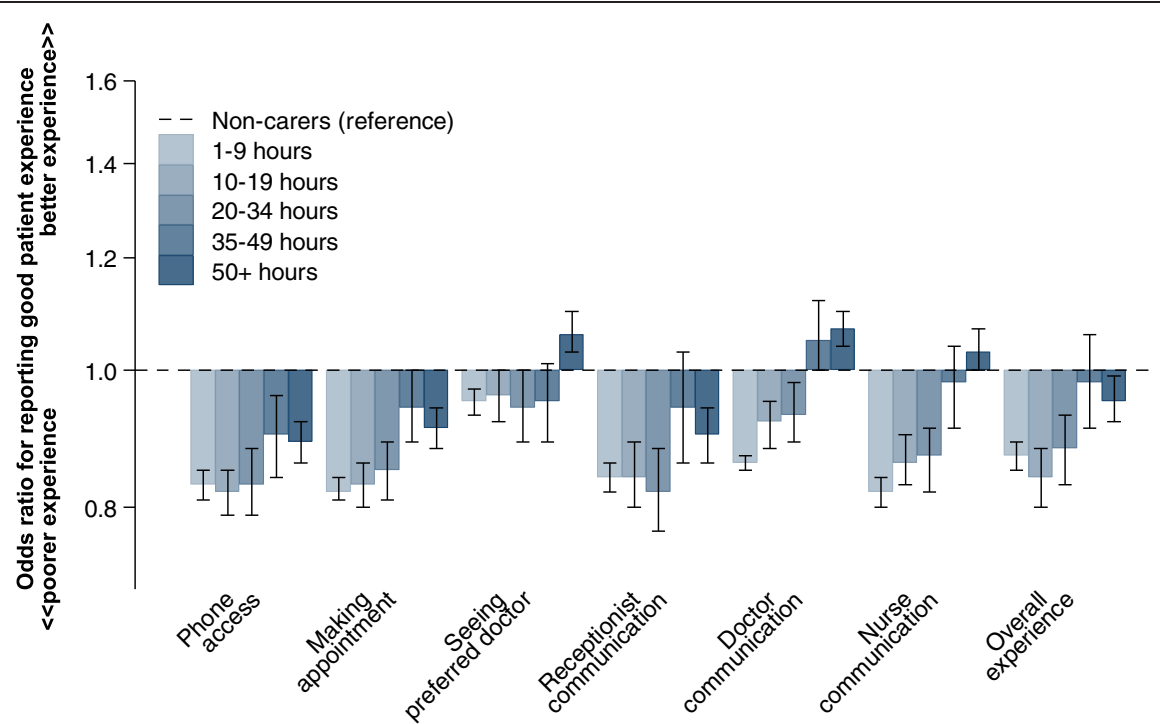

Fig. 2 Variation in primary care experiences among people with self-reported carer responsibilities, by weekly care commitment

Table 4 Differences in patient experience among carers

\begin{tabular}{|c|c|c|c|c|}
\hline & $\begin{array}{l}\text { Unadjusted predictors of positive } \\
\text { overall experience of care OR }(95 \% \mathrm{Cl})\end{array}$ & $p$-value & $\begin{array}{l}\text { Adjusted predictors of positive } \\
\text { overall experience of care OR }(95 \% \mathrm{Cl})^{\mathrm{a}}\end{array}$ & $p$-value \\
\hline \multicolumn{5}{|l|}{ Gender } \\
\hline Male & ref & $p=0.03$ & ref & $p<0.0001$ \\
\hline Female & 1.04 (1.00 to 1.07$)$ & & $1.16(1.12$ to 1.20$)$ & \\
\hline \multicolumn{5}{|l|}{ Age group } \\
\hline $18-24$ & 0.34 (0.32 to 0.37$)$ & $p<0.0001$ & 0.38 (0.35 to 0.41$)$ & $p<0.0001$ \\
\hline $25-34$ & 0.44 (0.41 to 0.47 ) & & 0.48 (0.45 to 0.51$)$ & \\
\hline $35-44$ & 0.62 (0.58 to 0.65$)$ & & 0.64 (0.61 to 0.68$)$ & \\
\hline $45-54$ & 0.74 (0.71 to 0.78$)$ & & 0.75 (0.72 to 0.78$)$ & \\
\hline $55-64$ & ref & & ref & \\
\hline $65-74$ & 1.79 (1.69 to 1.90$)$ & & 1.79 (1.69 to 1.90$)$ & \\
\hline $75-84$ & 2.61 (2.38 to 2.86$)$ & & 2.61 (2.38 to 2.86$)$ & \\
\hline $85+$ & 2.34 (1.93 to 2.82$)$ & & 2.35 (1.94 to 2.84$)$ & \\
\hline \multicolumn{5}{|l|}{ Ethnic group } \\
\hline White & ref & $p<0.0001$ & ref & $p<0.0001$ \\
\hline Mixed & 0.55 (0.46 to 0.65$)$ & & 0.80 (0.67 to 0.96$)$ & \\
\hline Asian & 0.40 (0.37 to 0.42$)$ & & $0.56(0.52$ to 0.59$)$ & \\
\hline Black & 0.90 (0.80 to 1.02$)$ & & $1.20(1.06$ to 1.36$)$ & \\
\hline Other ethnic group & 0.64 (0.58 to 0.72 ) & & 0.88 (0.78 to 0.98$)$ & \\
\hline \multicolumn{5}{|c|}{ Socio-economic deprivation } \\
\hline 1 (Affluent) & ref & $p<0.0001$ & ref & $p<0.0001$ \\
\hline 2 & 0.55 (0.46 to 0.65$)$ & & 0.98 (0.92 to 1.03$)$ & \\
\hline 3 & 0.40 (0.37 to 0.42 ) & & 0.94 (0.89 to 1.00$)$ & \\
\hline 4 & 0.90 (0.80 to 1.02 ) & & 0.89 (0.84 to 0.94$)$ & \\
\hline 5 (Deprived) & 0.64 (0.58 to 0.72 ) & & 0.86 (0.81 to 0.92 ) & \\
\hline
\end{tabular}

a Positive patient experience defined as endorsement of "very good" or "fairly good" in response to question "Overall, how would you describe your experience of your GP surgery?" Odds ratios <.1.0 represent a poorer patient experience. The results are presented adjusted for level of caring commitment, age, gender, deprivation, ethnicity and general practice 
Informal carers' experiences as patients in primary care

Carers in the present study reported less positive patient experiences in primary care than non-carers, particularly for questions relating to access. Though the effects were not large in size, this pattern persisted even after sociodemographic characteristics known to influence patient experience were accounted for [35, 46, 47]. Findings suggest that problems with access to primary care among informal carers persist, even in a UK setting where a national health system with universal coverage enables access to free healthcare for all residents.

Further research is needed to explain the positive trend we observed between increasing caring commitment and better patient experience: we suggest increasing frequency of contact with family physicians among carers with a higher time commitment may be a contributory factor.

Among carers in our study, worse primary care experience was associated with being male, younger, non-white, and living in a socially deprived area, findings consistent with previous studies examining patient experience in primary care [47-49].

\section{Study considerations}

Particular strengths of this study are the large sample size and use of data from a national primary care-based survey. Our findings contribute to existing literature in at least three important ways. First, this study is one of very few to provide information on the experiences of carers as patients in primary care (rather than in their role as carers for another patient). Second, our results highlight heterogeneity in quality of life among carers and identify younger carers as a priority. Finally, our results provide little empirical support for the hypothesis that small amounts of caring confer benefits to healthrelated quality of life for carers. We suggest future research considers how factors such as physical health influence the process of self-selection among potential caregivers, that is, potentially determining those who do, or do not, feel able to undertake a caring role.

This study also has some limitations. Data were collected through a national survey: we were reliant on respondents identifying themselves as informal carers, and no information on the nature of the caring relationship was available. In responding to survey questions, carers who encounter primary care in their capacity as a carer and, separately, as a patient, may have found it difficult to answer questions solely with their own experiences as a patient in mind. The response rate of $37.8 \%$ is modest, though comparable with other large patient experience surveys [37, 50, 51]. Women and older people are overrepresented among responders, and although people living in more deprived areas are less likely to respond overall, respondents come from all general practices in
England, and all levels of income are included. It is possible that respondents in poorer health, or who have experienced poorer patient experience, are under-represented, but we would not expect this to be differential between people with and without caring responsibilities. Although we cannot be sure of the nature of response bias between different groups of carers, we note that in general response rates have been found only weakly to be associated with non-response bias in similar surveys [52-56]. Finally, the experiences of English carers in our study may differ from those of carers other countries due to differences in the cultural importance of caregivers, the structure of health and social care systems, and documented differences in carer burden [20,57].

\section{Implications for policy and practice}

Findings from this study have practical implications for the practice of family medicine, and for health policy. One component of any strategy to improve carer health should be to encourage primary care practices to continually review their patients and compile a "register" of those providing informal care. This would then enable family physicians to identify those with high caring commitments [58] and to provide proactive support, for example, using existing instruments to identify pain, anxiety and depression among carers, treating where appropriate $[3,4,59]$. Difficulties with this approach include the often gradual way in which people become carers, and the fact that they often do not identify themselves as such [58]. However, selfidentification may be prompted by questions such as the one used in this study [36].

Interventions to improve carer health should consider evidence of heterogeneity among carers to ensure such interventions are targeted to those individuals who may benefit most and support is individualised. We recommend that family physicians focus on monitoring the overall health of younger carers and those living in deprived areas, and specific primary care interventions for these groups may need to be developed.

Improving the primary care experience of carers, particularly in relation to access, should be included as a strategic priority for health policy. A broad and coordinated approach from both policymakers and clinicians is needed in order to address the double disadvantage among informal carers of poorer health-related quality of life and poorer patient experience in primary care.

\section{Conclusions}

Informal carers experience a double disadvantage of poorer health-related quality of life and worse patient experience in primary care when compared to non-carers of similar age, gender, ethnicity and level of social deprivation. There is heterogeneity among carers in terms of their healthrelated quality of life, with those who are younger, from deprived areas or who have high caregiving commitments 
experiencing fewer days in full health. We found no evidence from this work to suggest that caregiving confers health benefit on the carer; while carers over 80 years reported better health-related quality of life overall than non-carers of the same age, they scored worse on pain and anxiety/depression.

Our study was novel in investigating the primary care experience of informal carers as patients themselves, rather than focusing on their role as carer for another patient. Carers reported worse patient experience than non-carers, particularly in terms of access, with those carers who were male, younger, non-white, or living in a socially deprived area rating their experiences the most poorly.

We recommend that strategies to improve the wellbeing of informal carers focus on identifying caregivers, including those who are young or living in socially deprived areas, and address carers' individual health needs including the treatment of pain and anxiety/depression. Improving the primary care patient experience for informal carers, particularly in terms of access, is an important priority.

\section{Additional files}

Additional file 1: Table S1. Item content for seven questions from the General Practice Patient Survey 2012. Figure S1. The association between caring and health-related quality of life, presented separately for each domain of EQ-5D.

Additional file 2: Table S2. Likelihood of reporting a poorer overall patient experience among carers of different levels of caring commitment.

\section{Abbreviations}

GP: General Practitioner/ General Practice; EQ-5D: EuroQuol five-dimension; UK: United Kingdom; OR: Odds Ratio; Cl: Confidence Interval; UK: United Kingdom.

\section{Competing interests}

MR has acted as adviser to the English Department of Health in the development of the English pay-for-performance scheme (the Quality and Outcomes Framework) and on the development of the General Practice Patient Survey. Other authors have no conflicts of interest to declare.

\section{Authors' contributions}

All authors had full access to all of the data in the study and take responsibility for the integrity of the data and accuracy of the data analysis. CP conceived of the research questions. CS and GT completed the statistical analysis: All authors (GT, CS, MR and CP) reviewed/edited the manuscript and contributed to discussion. CP is the guarantor of the paper. All authors read and approved the final manuscript.

\section{Acknowledgements}

We would like to acknowledge and thank Dr Gary Abel (Senior Research Associate-statistician) for his supervision and statistical support for this paper. This research was undertaken as a student selected component by GT during undergraduate medical training. As such, no external funding was obtained.

\section{Author details}

${ }^{1}$ Cambridge Centre for Health Services Research Primary Care Unit, University of Cambridge, Cambridge, UK. ${ }^{2}$ RAND Europe, Cambridge, UK. ${ }^{3}$ Department of Psychology, Anglia Ruskin University, Cambridge, UK.
Received: 10 August 2014 Accepted: 6 May 2015

Published online: 15 May 2015

\section{References}

1. Talley RC, Crews JE. Framing the public health of caregiving. Am J Public Health. 2007:97:224-8.

2. Disability and Health-Healthy People [http://www.healthypeople.gov/2020/ topicsobjectives2020/objectiveslist.aspx?topicld=9]

3. Supporting Carers: An Action Guide for General Practitioners and Their Teams. Second Edition. London, UK: The Princess Royal Trust for Carers, The Royal College of General Practitioners; 2011, p. 20-33.

4. Collins L, Swartz K. Caregiver care. Am Fam Physician. 2011;83:1309-17.

5. Caregiving in the U.S. 2009. Bethesda, MD, USA: National Alliance for Caregiving, AARP; 2009

6. White C. 2011 census analysis: unpaid care in England and Wales, 2011 and comparison with 2001. London: Office for National Statistics; 2013.

7. Disability, Ageing and Carers, Australia, Summary of findings, 2012 [http://www.abs.gov.au/AUSSTATS/abs@.nsf/Lookup/4430.0Main +Features12012?OpenDocument].

8. Hirst M. Health inequalities and informal care: End of project report. York, UK: The University of York Social Policy Research Unit; 2004.

9. House of Lords Select Committee on Public Service Demographic Change. Ready for ageing? Report of session 2012-13. London, UK: The Stationery Office; 2013.

10. Buckner L, Yeandle S. Valuing carers 2011; calculating the value of Carers' support. Leeds, UK: Carers UK, University of Leeds; 2011

11. Feinberg L, Reinhard SC, Houser A, Choula R. Valuing the invaluable: 2011 update-the growing contributions and costs of family caregiving. Washington, DC, USA: AARP Public Policy Institute; 2011.

12. Pickard L. Informal care for older people provided by their adult children: projections of supply and demand to 2041. Report to the strategy unit (cabinet office) and the Department of Health. London, UK: Personal Social Services Research Unit; 2008.

13. Institute of Medicine. Retooling for an aging America: building the health care workforce. Washington, DC, USA: The National Academies Press; 2008

14. Vitaliano PP, Zhang J, Scanlan JM. Is caregiving hazardous to one's physical health? a meta-analysis. Psychol Bull. 2003;129:946-72.

15. Pinquart $M$, Sörensen $S$. Differences between caregivers and noncaregivers in psychological health and physical health: a meta-analysis. Psychol Aging 2003;18:250-67.

16. The NHS Information Centre Social Care Team. Survey of carers in households-England, 2009-10. Leeds, UK: Health \& Social Care Information Centre; 2010.

17. Doran T, Drever F, Whitehead M. Health of young and elderly informal carers: analysis of UK census data. BMJ. 2003;327:1388.

18. Evercare Study of Caregivers in Decline: A Close-up Look at the Health Risks of Caring for a Loved One. Minnetonka, MN, USA: Evercare, National Alliance for Caregiving; 2006, p. 5-32.

19. Schulz R. Caregiving as a risk factor for mortality: the caregiver health effects study. JAMA, J Am Med Assoc. 1999;282:2215-9.

20. Dujardin C, Farfan-Portet M-I, Mitchell R, Popham F, Thomas I, et al. Does country influence the health burden of informal care? an international comparison between Belgium and great Britain. Soc Sci Med. 2011;73:32-1123.

21. Anderson LA, Edwards VJ, Pearson WS, Talley RC, McGuire LC, Andresen EM. Adult caregivers in the United States: characteristics and differences in well-being, by caregiver age and caregiving status. Prev Chronic Dis. 2013;10, E135

22. Tommis Y, Robinson CA, Seddon D, Woods B, Perry J, Russell IT. Carers with chronic conditions: changes over time in their physical health. Chronic IIIn. 2009;5:155-64.

23. Legg L, Weir CJ, Langhorne P, Smith LN, Stott DJ. Is informal caregiving independently associated with poor health? a population-based study. J Epidemiol Community Health. 2013;67:95-7.

24. Adelman RD, Tmanova LL, Delgado D, Dion S, Lachs MS. Caregiver burden: a clinical review. JAMA, J Am Med Assoc. 2014;311:1052-60.

25. Pinquart $M$, Sörensen S. Correlates of physical health of informal caregivers: a meta-analysis. J Gerontol B Psychol Sci Soc Sci. 2007;62:P126-37.

26. Brown SL, Smith DM, Schulz R, Kabeto MU, Ubel PA, Poulin M, et al. Caregiving behavior is associated with decreased mortality risk. Psychol Sci. 2009;20:488-94. 
27. Roth DL, Haley WE, Hovater M, Perkins M, Wadley VG, Judd S. Family caregiving and all-cause mortality: findings from a population-based propensity-matched analysis. Am J Epidemiol. 2013;178:1571-8.

28. Brown SL, Nesse RM, Vinokur AD, Smith DM. Providing social support may be more beneficial than receiving it: results from a prospective study of mortality. Psychol Sci. 2003;14:320-7.

29. Buyck J-F, Bonnaud S, Boumendil A, Andrieu S, Bonenfant S, Goldberg M, et al. Informal caregiving and self-reported mental and physical health: results from the gazel cohort study. Am J Public Health. 2011;101:1971-9.

30. McCann JJ, Hebert LE, Bienias JL, Morris MC, Evans DA. Predictors of beginning and ending caregiving during a 3-year period in a biracial community population of older adults. Am J Public Health. 2004;94:1800-6.

31. Fredman L, Doros G, Ensrud KE, Hochberg MC, Cauley JA. Caregiving intensity and change in physical functioning over a 2-year period: results of the caregiver-study of osteoporotic fractures. Am J Epidemiol. 2009;170:203-10.

32. Perreault $M$, Rousseau M, Provencher $H$, Roberts $S$, Milton D. Predictors of caregiver satisfaction with mental health services. Community Ment Health J. 2012:48:232-7.

33. Doyle C, Lennox L, Bell D. A systematic review of evidence on the links between patient experience and clinical safety and effectiveness. BMJ Open. 2013;3:e001570.

34. Llanwarne NR, Abel GA, Elliott MN, Paddison CAM, Lyratzopoulos G, Campbell $J$, et al. Relationship between clinical quality and patient experience: analysis of data from the English Quality and Outcomes Framework and the National GP Patient Survey. Ann Fam Med. 2013;11:467-72.

35. Paddison C, Elliott M, Parker R, Staetsky L, Lyratzopoulos G, Campbell JL, et al. Should measures of patient experience in primary care be adjusted for case mix? evidence from the English general practice patient survey. BMJ Qual Saf. 2012;21:634-40.

36. Ipsos MORI. Technical annex for the GP patient survey 2011-12. London, UK: Ipsos MORI; 2012.

37. Roland M, Elliott M, Lyratzopoulos G, Barbiere J, Parker RA, Smith P, et al. Reliability of patient responses in pay for performance schemes: analysis of national general practitioner patient survey data in England. BMJ. 2009:339:b3851.

38. EuroQol: EuroQol-About EQ-5D [http://www.euroqol.org/about-eq-5d.html]

39. Dolan P. Modeling valuations for EuroQol health states. Med Care. 1997:35:1095-108

40. GPPS Practice Results [http://practicetool.gp-patient.co.uk/practice]

41. Office for National Statistics: Primary Set of Harmonised Concepts and Questions. [http://www.ons.gov.uk/ons/guide-method/harmonisation/ primary-set-of-harmonised-concepts-and-questions/index.html].

42. McLennan D, Barnes H, Noble M, Davies J, Garratt E, Dibben C. The English indices of deprivation 2010. London, UK: Department for Communities and Local Government; 2011.

43. Becker F, Becker S. Young adult carers in the UK experiences, needs and services for carers aged 16-24. London, UK: The Princess Royal Trust for Carers; 2008

44. Rodakowski J, Skidmore ER, Rogers JC, Schulz R. Role of social support in predicting caregiver burden. Arch Phys Med Rehabil. 2012;93:2229-36.

45. Uphoff EP, Pickett KE, Cabieses B, Small N, Wright J. A systematic review of the relationships between social capital and socioeconomic inequalities in health: a contribution to understanding the psychosocial pathway of health inequalities. Int J Equity Health. 2013;12:54.

46. O'Malley AJ, Zaslavsky AM, Elliott MN, Zaborski L, Cleary PD. Case-mix adjustment of the CAHPS hospital survey. Health Serv Res. 2005;40(6 Pt 2):2162-81.

47. Lyratzopoulos G, Elliott M, Barbiere JM, Henderson A, Staetsky L, Paddison C, et al. Understanding ethnic and other socio-demographic differences in patient experience of primary care: evidence from the English general practice patient survey. BMJ Qual Saf. 2012;21:21-9.

48. Mead N, Roland M. Understanding why some ethnic minority patients evaluate medical care more negatively than white patients: a cross sectional analysis of a routine patient survey in English general practices. BMJ. 2009;339:b3450.

49. Weech-Maldonado R, Morales LS, Elliott M, Spritzer K, Marshall G, Hays RD. Race/ethnicity, language, and patients' assessments of care in Medicaid managed care. Health Serv Res. 2003;38:789-808
50. Jha AK, Orav EJ, Zheng J, Epstein AM. Patients' perception of hospital care in the United States. N Engl J Med. 2008;359:1921-31.

51. Lyratzopoulos G, Elliott MN, Barbiere JM, Staetsky L, Paddison CA, Campbell J, et al. How can health care organizations be reliably compared?: Lessons from a national survey of patient experience. Med Care. 2011;49:724-33.

52. Groves RM, Peytcheva E. The impact of nonresponse rates on nonresponse bias a meta-analysis. Public Opin Q. 2008;72:167-89.

53. Groves RM, Fowler FJ, Couper MP, Lepkowski JM, Singer E, Tourangeau R. Surbey methodology. 2nd ed. New York: Wiley; 2011. p. 183-216.

54. Davern M. Nonresponse rates are a problematic indicator of nonresponse bias in survey research. Health Serv Res. 2013;48:905-12.

55. Johnson TP, Wislar JS. Response rates and nonresponse errors in surveys. JAMA. 2012;307:1805-6.

56. Halbesleben JRB, Whitman MV. Evaluating survey quality in health services research: a decision framework for assessing nonresponse bias. Health Serv Res. 2013;48:913-30.

57. Caroline Glendenning. Support for carers of older people-some intranational and national comparisons. London, UK: Audit Commission; 2003.

58. Carduff E, Finucane A, Kendall M, Jarvis A, Harrison N, Greenacre J, et al. Understanding the barriers to identifying carers of people with advanced illness in primary care: triangulating three data sources. BMC Fam Pract. 2014;15:48.

59. Bjelland I, Dahl AA, Haug TT, Neckelmann D. The validity of the hospital anxiety and depression scale. An updated literature review. J Psychosom Res. 2002;52:69-77.

\section{Submit your next manuscript to BioMed Central and take full advantage of:}

- Convenient online submission

- Thorough peer review

- No space constraints or color figure charges

- Immediate publication on acceptance

- Inclusion in PubMed, CAS, Scopus and Google Scholar

- Research which is freely available for redistribution 